\title{
Moving towards more equitable and integrated approaches for tobacco control and non-communicable diseases: invited commentary
}

\author{
Asaf Bitton ${ }^{1,2}$
}

Wipfli and Samet incisively describe the many challenges that the global noncommunicable disease (NCD) movement faces, and the lessons tobacco control can offer it. ${ }^{1}$ Notably though, while global tobacco control offers one of the few proven strategies for NCD control, its successes have not been spread equally around the world. An inverse gradient of tobacco control success is emerging between wealth and tobacco burden (within and between countries). Stunning successes in reducing high tobacco use in the USA, Western Europe and Latin America stand in tandem with the large and often growing burdens of use and tobacco-induced disease in East Asia, parts of the former Soviet Union and Africa. The FCTC is a monumental transnational

\footnotetext{
${ }^{1}$ Division of General Medicine, Brigham and Women's Hospital, Boston, Massachusetts, USA; ${ }^{2}$ Department of Health Care Policy, Harvard Medical School, Boston, Massachusetts, USA

Correspondence to Dr Asaf Bitton, Division of General Medicine, Brigham and Women's Hospital, 1620 Tremont Street, 3rd Floor, Rm 3-002P, Boston, MA 02120, USA; abitton@partners.org
}

public health achievement, but has had uneven and delayed implementation in these high-burden poorer countries. Moreover, NCDs and tobacco share a tragic and often overlooked realityboth are growing disproportionately among the poor, the young and socially marginalised. $^{2}{ }^{3}$ This picture should spur action in both tobacco control and NCD civil society to promote a human rights-based approach that preferentially emphasises equity, access and implementation of both evidence-based treatments and policies.

A consensus is emerging in the NCD community that a broader 'diagonal' approach is necessary, emphasising both health systems strengthening and focused disease and risk factor targeting. ${ }^{4}$ But recent experience with broad health systems reform in poor countries showed limited success, and may have actually delayed adequate responses to emerging threats such as HIV. It was the belated realisation that effective HIV control required both prevention and treatment integrated within better functioning systems that finally spurred HIV burden reductions. ${ }^{5}$ Here tobacco control stands to learn well from these failures and promote a combined public health and treatment approach for NCDs. Tobacco control advocates should move beyond the stale debate around the cost-effectiveness of individual treatment versus populationbased tobacco control measures. There is a clear ethical mandate to do both, ${ }^{6}$ and an evidence base that suggests that both are necessary to reduce population burden and immediately help those who cannot quit on their own today. ${ }^{7}$

\section{Competing interests None.}

Provenance and peer review Commissioned; internally peer reviewed.

Tobacco Control 2012;21:273.

doi:10.1136/tobaccocontrol-2011-050369

\section{REFERENCES}

1. Wipfli H, Samet J. Moving beyond global tobacco control to global disease control. Tobacco Control 2012;21:269-72.

2. NCD Alliance Briefing Paper. NCDs, Tobacco Control, and the FCTC. 2011. http://www.fctc.org/images/ stories/NCDs tobacco brief June11.pdf laccessed 5 Dec 2011)

3. Kishore SP, Siegel KR, Ahmad A, et al; The Young Professionals' Chronic Disease Network. Youth manifesto on non-communicable diseases. Global Heart 2011;6:201-10

4. Frenk J. The global health system: strengthening National health systems as the Next Step for global Progress. PLoS Med 2010;7:e1000089. http://www. ncbi.nlm.nih.gov/pubmed/15255381

5. Walton DA, Farmer PE, Lambert W, et al. Integrated HIV prevention and care strengthens primary health care: lessons from rural Haiti. J Public Health Policy 2004;25:137-58.

6. Bitton A, Eyal N. Too poor to treat? The complex ethics of cost-effective tobacco policy in the developing World. Public Health Ethics 2011;4:109-20.

7. Jha $\mathbf{P}$, Chaloupka FJ, Moore J, et al. Tobacco addiction. In: Jamison DT, Breman JG, Measham AR, et al, eds. Disease Control Priorities in Developing Countries. 2nd edn. New York: Oxford University Press, 2006:869-86. 